\title{
The Receptor for Advanced Glycation Endproducts Does Not Contribute to Pathology in a Mouse Mesenteric Ischemia/Reperfusion-Induced Injury Model
}

OPEN ACCESS

Edited by:

Uday Kishore,

Brunel University London, UK

Reviewed by:

Paul Quax,

Leiden University Medical Center,

Netherlands

Dalil Hannani,

$P D C^{*}$ line Pharma, France

*Correspondence:

Trent M. Woodruff t.woodruff@uq.edu.au

Specialty section:

This article was submitted to Molecular Innate Immunity, a section

of the journal Frontiers in Immunology

Received: 22 September 2015 Accepted: 23 November 2015 Published: 07 December 2015

Citation:

Wu MCL, Gilmour TD, Mantovani S and Woodruff TM (2015) The

Receptor for Advanced Glycation Endproducts Does Not Contribute to

Pathology in a Mouse Mesenteric Ischemia/Reperfusion-Induced Injury Model.

Front. Immunol. 6:614. doi: 10.3389/fimmu.2015.00614

\author{
Mike C. L. Wu, Timothy D. Gilmour, Susanna Mantovani and Trent M. Woodruff ${ }^{\star}$ \\ School of Biomedical Sciences, The University of Queensland, Brisbane, QLD, Australia
}

The receptor for advanced glycation endproducts (RAGE) can engage a diverse class of ligands and contribute to the immune and inflammatory response to infection and injury. It is known to be a pathogenic receptor in many inflammatory diseases, including ischemia/reperfusion (IR) injuries in several tissues; however, its role has not been investigated in IR injuries of the intestine to date. Mesenteric (or intestinal) IR leads to recruitment of inflammatory cells into intestinal interstitial spaces, which markedly disrupts intestinal mucosa. IR-induced mucosal injury is accompanied by the development of a local and systemic inflammatory response and remote organ injury, and results in high mortality in the clinic. We hypothesized that elimination of RAGE signaling using RAGE ${ }^{-/-}$ mice would result in decreased local and remote organ injury and reduced inflammation in a mesenteric IR model, and thus be a target for therapeutic intervention. We found that RAGE ligands including HMGB-1 and C3a were elevated after mesenteric IR indicating the potential for enhanced RAGE activation in this model. However despite this, wild-type and $\mathrm{RAGE}^{-1-}$ mice both displayed similar degrees of mesenteric injury, neutrophil infiltration, intestinal edema, cytokine generation, neutrophil mobilization, and remote organ injury after mesenteric IR. We, therefore, conclude that despite its role in other organ IR injuries, and the robust production of RAGE ligands after intestinal ischemia, RAGE itself does not directly influence tissue injury and the inflammatory response in mesenteric $\mathbb{I R}$.

Keywords: ischemia-reperfusion injury, RAGE, HMGB-1, C3a, neutrophils, small intestine

\section{INTRODUCTION}

The gastrointestinal tract takes up a significant portion of individual circulating blood, and a decrease in blood supply to the intestine even for a short period due to systemic hypotension, major cardiovascular surgery or trauma, can lead to intestinal ischemia (1). Delayed presentation of intestinal ischemia renders the in-hospital mortality rate still above $60 \%$ (2). Clinicians also encounter the problems associated with the salvage of ischemic gut, where reperfusion leads to a local and systemic inflammatory response that exacerbates tissue destruction and other complications, termed ischemia/reperfusion (IR) injuries (3).

The receptor for advance glycation endproducts (RAGE) is a transmembrane innate immune receptor that upon ligation can induce a variety of inflammatory responses and oxidative stress $(4,5)$. 
RAGE is capable of interacting with several ligands, including its namesake glycoprotein advanced glycation endproducts (AGE), high-mobility group protein box 1 (HMGB-1), S100 proteins, and complement fragment $3 a$ (C3a) $(6,7)$. Given the large number of RAGE ligands associated with the inflammatory response, activation of this receptor has a critical impact on facilitating chronic diseases via chronic inflammation, for example diabetic conditions and Alzheimer's disease $(8,9)$. It is also strongly implicated in the pathogenesis of IR injuries, with several studies demonstrating genetic deficiency or inhibition of RAGE to be protective in IR injuries to the heart, liver, lung, and brain (10-13). To date, however, no studies have addressed whether RAGE is pathogenic during the development of intestinal IR injury.

Intestinal IR injuries in the mouse lead to a variety of pathological sequela including mobilization and recruitment of neutrophils, oxidative damage, edema, production of inflammatory cytokines, and systemic inflammation leading to remote organ injury (14). Given that RAGE activation can contribute to many of these same pathways and inhibition of RAGE is protective in IR injuries of other organs, this suggests that RAGE blockade could be a therapeutic target for treating intestinal IR injuries. In this study, we therefore aimed to determine the pathogenic role of RAGE in intestinal IR injury. We first measured RAGE ligand levels after mesenteric IR and then measured mucosal damage in RAGE deficient ( $\mathrm{RAGE}^{-/-}$) mice. In addition, inflammatory cells, inflammatory mediators, and injury markers were also measured. Interestingly, we found that despite an upregulation of RAGE ligands following mesenteric IR, deficiency of RAGE did not impact on the disease pathology, suggesting other signaling pathways predominate in this model.

\section{MATERIALS AND METHODS}

\section{Animals}

Male C57BL/6 wild-type (WT) mice and RAGE signalingdeficient mice $\left(\mathrm{RAGE}^{-/-}\right.$) on a $\mathrm{C} 57 \mathrm{BL} / 6 \mathrm{~J}$ genetic background were maintained at the University of Queensland's Biological Resources Animal Facilities under specific pathogen free conditions. Male mice aged 10-12 weeks weighing 20-25g were selected for all experiments. Homozygous $\mathrm{RAGE}^{-1-}$ mice have the extracellular domain of RAGE (exons 2-7) removed and thus express a non-functional RAGE protein $(15,16)$. The experimental protocols were approved by the University of Queensland's Animal Ethics Committee.

\section{Intestinal Ischemia Reperfusion Injury Model}

Mice were anesthetized by a ventilated system containing $4 \%$ of isoflurane with oxygen supply $(2 \mathrm{~L} / \mathrm{min})$ during the surgical operation. To induce mesenteric IR, the superior mesenteric artery (SMA) was exposed and occluded with a loop ligature for $30 \mathrm{~min}$ to induce non-traumatic intestinal ischemia as previously described $(17,18)$. The ligature was then removed to allow intestinal tissue reperfusion for $150 \mathrm{~min}$, which results in moderate-severe intestinal damage (18). Both WT and $\mathrm{RAGE}^{-1-}$ mice underwent IR surgery. To establish a baseline, sham-operated WT mice underwent the same surgical procedures, but the SMA was not occluded. Following the reperfusion phase, mice were then euthanatized, and pieces of intestinal tissue from the distal jejunum/early ileum and whole blood [collected in $1 \mathrm{mg} / \mathrm{mL}$ EDTA and $0.1 \mathrm{mg} / \mathrm{mL}$ nafamostat mesylate (19)] were obtained for other analyses described below.

\section{Histology and Tissue Injury Evaluation}

Tissues were fixed in $4 \%$ paraformaldehyde (Sigma-Aldrich, USA) for a minimum of $72 \mathrm{~h}$ and embedded in paraffin. Tissue sections $(6 \mu \mathrm{m})$ were stained with hematoxylin and eosin (H\&E) by following a standard H\&E staining protocol. Tissue injury score was determined in a blinded fashion using a graded scale adapted from Chiu et al. (20).

\section{Wet/Dry Weight}

A portion of the intestine $(5-10 \mathrm{~cm})$ was weighed to obtain wet weight $(\mathrm{g})$. The tissue was allowed to dry for $48 \mathrm{~h}$ at $80^{\circ} \mathrm{C}$ and weighed for dry weight. Wet/dry weight ratio, as a measure of edema, was calculated by the formula: wet weight $(\mathrm{g}) / \mathrm{dry}$ weight (g).

\section{Myeloperoxidase Level}

Neutrophil accumulation and activation in the tissue was quantitated by the level of myeloperoxidase enzyme in the tissue. A portion of intestine was homogenized and sonicated in phosphate buffered saline (PBS; $\mathrm{pH}$ 6.0) containing $1 \%$ protease inhibitor cocktail (Merck-Millipore, USA) and $0.5 \% \mathrm{Hta}-\mathrm{Br}$ (Sigma-Aldrich, USA). The homogenate was incubated with the substrate containing $2.85 \mathrm{mg} / \mathrm{mL} \mathrm{O}$-dianisidine and $2.3 \%$ hydrogen peroxide in deionized water. The absorbance of the sample was then measured spectrophotometrically at $460 \mathrm{~nm}$ at $15 \mathrm{~min}$ and normalized to the total protein level of the homogenate measured by BCA protein Assay (Thermo Fisher Scientific, Australia).

\section{Intestinal Neutrophil Staining (Leder's Stain)}

Neutrophils in the intestine were stained using a naphthol AS-D chloroacetate esterase cytochemical staining kit (Sigma-Aldrich, USA), which identifies specific leukocyte esterases predominantly expressed in granulocytic neutrophils. Harvested tissues were fixed in $4 \%$ paraformaldehyde, embedded in paraffin and, microtome sectioned and then stained with naphthol esterase solution, according to the manufacturer's protocol. Cells with bright-red granulations in the mucosa were counted in a blinded method and expressed as the number of neutrophils per villus.

\section{Leukocyte and Neutrophil Count}

EDTA blood $(1 \mathrm{mg} / \mathrm{mL})$ was collected from the inferior venacava and centrifuged. White blood cells were isolated by lysing erythrocytes with red blood cell lysis solution $(0.85 \%$ ammonium chloride in PBS) followed by hypotonic shock (21). Total leukocyte numbers were determined by using an up-right light microscopy and a hematocytometer. The neutrophil population (\%) was identified and counted in triplicate blood smears stained by Diff-Quik staining kit (Thermo Fisher Scientific, Australia). Circulating neutrophil counts were calculated by multiplying total white blood cell count (cells per millilitre) to neutrophil population (\%). 


\section{Alanine Transaminase and Alkaline Phosphatase}

Liver injury was quantified by measuring alanine transaminase (ALT) and alkaline phosphatase (ALP) levels in the plasma as previously described (22) and according to the manufacturer's instructions (ALT and ALP reagents; Thermo Fisher Scientific, Australia).

\section{Inflammatory Protein Levels}

Plasma cytokines, HMGB-1, and IL-6 and complement factor C3a levels were measured by enzyme-linked immunosorbent (ELISA) kits (Chondrex, USA; BD Biosciences, Australia), according to their manufacturers' instructions. The concentrations of these proteins for the samples were calculated by using a linear regression analysis of their correspondent standard curves.

\section{Statistics}

All experimental results are expressed as mean \pm SEM. Data analysis was performed using GraphPad Prism 6.0 software (GraphPad software, Inc., USA). Statistical comparisons were made using a one-way ANOVA with Dunnett's post-test, or $t$-test (two-tailed distribution).

\section{RESULTS}

\section{Mesenteric IR Induces Release of Ligands for RAGE}

There are several molecules that are reported to interact with RAGE and that include the damage-associated molecular pattern (DAMP) molecule, secreted HMGB-1, and the complement activation fragment $\mathrm{C} 3 \mathrm{a}$, both of which are generated following tissue injury $(6,7)$. To assess whether our mouse model of IR injury generated these RAGE ligands, HMGB-1 and C3a systemic blood concentrations were measured by using standard ELISAs. The plasma concentration of HMGB-1 was dramatically increased by approximately 12-fold following IR, compared to sham-operated IR mice (Figure 1A). We also found a twofold increase in C3a plasma concentrations after IR compared to sham-operated mice (Figure 1B). These data show that the intestinal IR setting induced elevations of RAGE ligands in the circulation, and thus indicates the potential for enhanced RAGE activation after mesenteric IR.

\section{Elimination of RAGE Does Not Reduce Mucosal Injury Following Mesenteric IR}

Mesenteric IR induces a marked damage to intestinal mucosa. In our study, haemotoxylin and eosin staining demonstrated mesenteric IR-induced mucosal damage which included villus epithelial lifting/loss and lamina propria swelling (Figure 2A), compared sham-operation (Figure 2B). This mucosal damage caused by IR was not mitigated in RAGE deficient $\left(\mathrm{RAGE}^{-/-}\right)$mice undergoing IR (Figure 2C). Tissue damage was semi-quantitated by scoring tissue from individual mice in a blinded manner, demonstrating elimination of RAGE had no significant impact on intestinal injury scores after IR (Figure 2D).

Next, tissue edema was measured as an indicator of vascular leakage of a common pathological event following mucosal damage. Mesenteric IR induced an increase in intestinal wet/dry weight ratios, however, elimination of RAGE had no impact on the water content in the intestine after IR (Figure 2E).

Neutrophils are a key player of the villi destruction in intestinal IR injury (14). We examined neutrophil accumulation by staining intestinal sections for neutrophils and measuring myeloperoxidase levels in the IR-injured intestines (18). As expected, IR induced a marked increase in neutrophil accumulation in the injured intestine and increased myeloperoxidase levels; however, elimination of RAGE did not show any significant alteration in neutrophil accumulation after IR (Figures 2F,G).

\section{Elimination of RAGE Does Not Impact White Blood Cell and Neutrophil Mobilization Following Mesenteric IR}

We have previously shown that intestinal reperfusion is strongly accompanied by a rapid mobilization of leukocytes (predominantly neutrophils) from bone marrow reservoirs into the circulation (18). Furthermore, the degree of neutrophil mobilization is correlated to the degree of neutrophil infiltration into the reperfused intestine and subsequent intestinal injury, and thus a key disease parameter of the potential for IR injury (18). As in our prior studies, mesenteric IR induced increases in both circulating white blood cells (Figure 3A), which were chiefly neutrophils (Figure 3B). However, again as for mucosal injury markers, the numbers of mobilized leukocytes or neutrophils were not affected by eliminating RAGE signaling (Figures 3A,B).
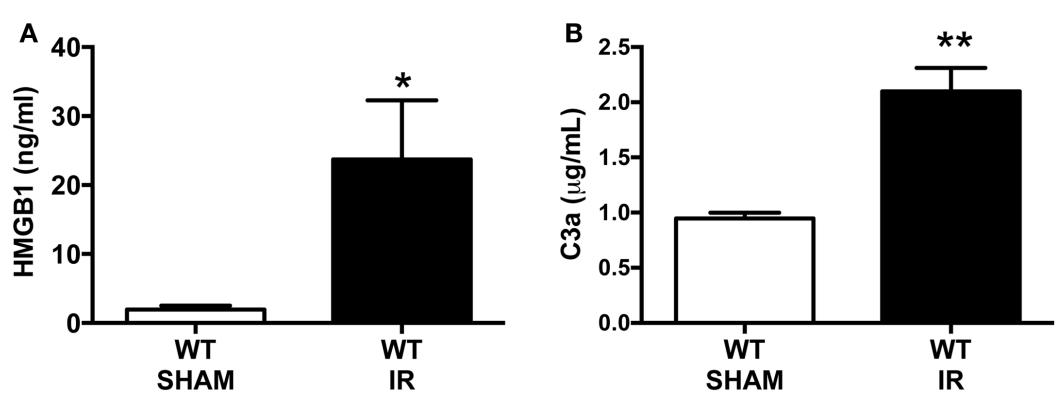

FIGURE 1 | Intestinal ischemia reperfusion (IR) injury induces systemic blood elevation of RAGE ligands. Wild-type (WT) mice were subjected to 30 min mesenteric artery occlusion, followed by $150 \mathrm{~min}$ of reperfusion to induce intestinal IR injury. Alternatively, sham-operated mice underwent the same procedure, except the mesenteric artery was not occluded (SHAM). The plasma levels of (A) HMGB1 and (B) C3a were measured using standard ELISA kits at the end of the reperfusion period. Data are presented as mean $\pm \mathrm{SEM}, n=4(\mathrm{WT}-\mathrm{SHAM}) n=8\left(\mathrm{WT}\right.$-IR) where ${ }^{*} p<0.05,{ }^{* *} p<0.01$ compared with WT-SHAM. 


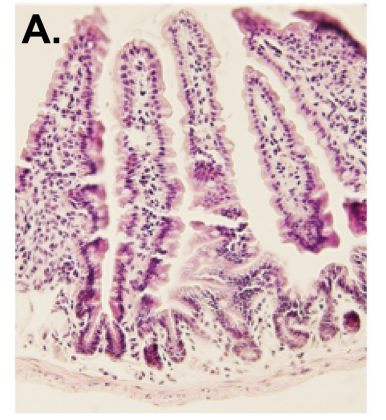

D.

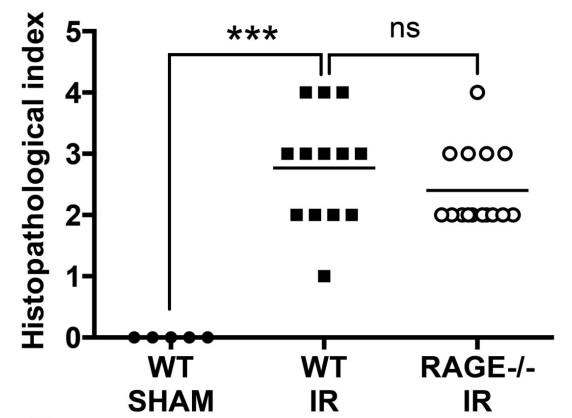

F.

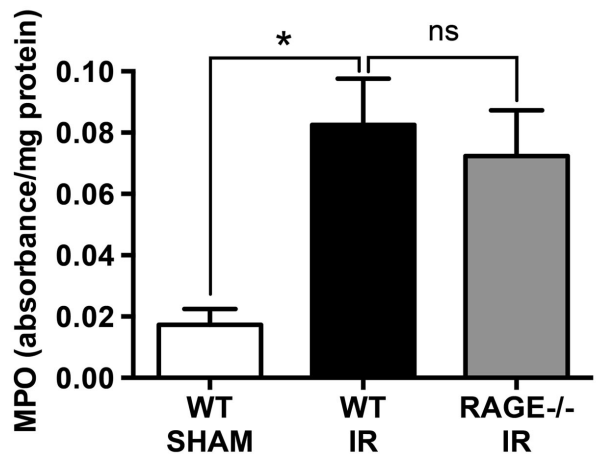

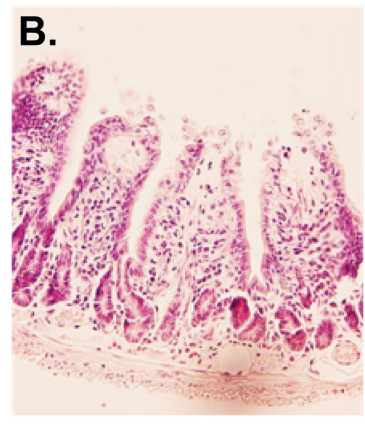

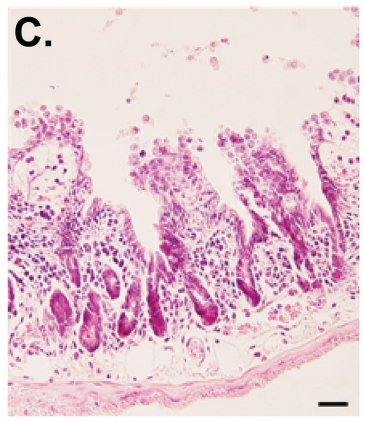

E.

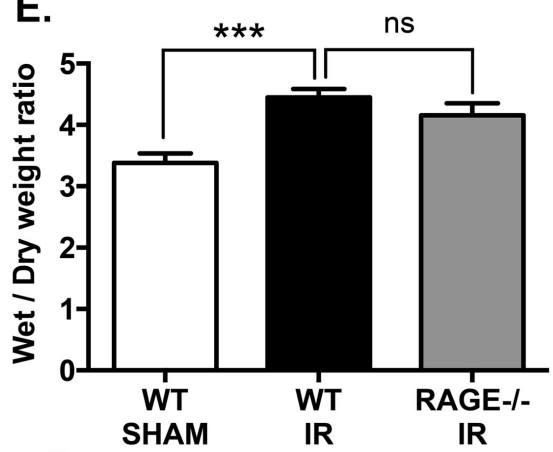

G.

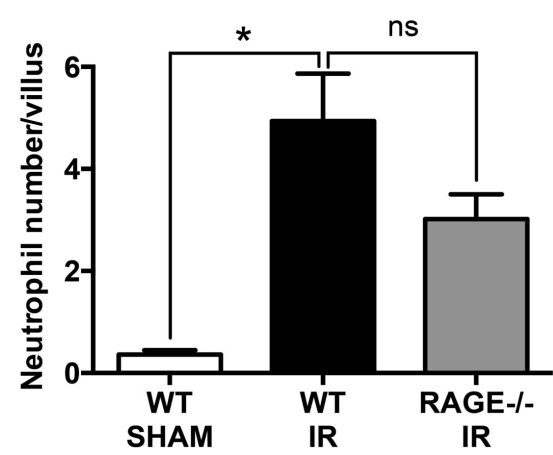

FIGURE 2 | Elimination of RAGE signaling does not impact mucosal damage and neutrophil accumulation following mesenteric IR. Mice were subjected to 30 min mesenteric artery occlusion, followed by 150 min reperfusion. (A-C) Representative H\&E staining of cross-sections of ileum from (A) sham-operated wild-type mice (WT-SHAM), (B) mesenteric IR wild-type mice (WT-IR), and (C) mesenteric IR RAGE ${ }^{-/-}$mice (RAGE ${ }^{-/-}$IR) groups. Scale bar $=50 \mu \mathrm{m}$. The mucosal injury was semi-quantitated as expressed as histopathological index (D) demonstrating no significant effect on IR injury following RAGE elimination. Increases in intestinal edema, as measured by wet/dry weight ratios (E), were also not impacted by RAGE signaling elimination. Similar results were seen following quantification of myeolperoxidase levels in intestinal homogensates, normalized by total protein levels (F), and esterase stained (Leder's) neutrophil counts in the entire cross-section of intestine and normalized to number of villi (G). Data are presented as mean \pm SEM, $n=5(\mathrm{WT}-\mathrm{SHAM}) ; n=13(\mathrm{WT}-\mathrm{IR}) ; n=15$ (RAGE ${ }^{-/-}$ IR) where ${ }^{\star} p<0.05,{ }^{\star \star \star} p<0.001$, and ns $=$ not-significant $(p>0.05)$.

\section{Elimination of RAGE Does Not Reduce Remote Organ (Liver) Injury and Systemic Inflammation Following Mesenteric IR}

Systemic inflammation and remote organ injury are often complications in intestinal IR injury $(23,24)$, which can lead to significant morbidity and mortality. We, therefore, finally examined liver injury markers, alanine aminotransferase (ALT), and ALP and pro-inflammatory mediators, including HMGB-1 and interleukin-6 (IL-6) in the peripheral blood after mesenteric IR. We found IR-induced significant elevations in plasma ALT and ALP, however as in the other parameters, elimination of RAGE did not significantly alter these elevations (Figures 4A,B). Moreover,
HMGB-1 and IL-6 concentrations in the plasma were significantly increased following mesenteric IR. However, these two proinflammatory proteins were not altered in $\mathrm{RAGE}^{-/-}$mice after IR (Figures 4C,D).

\section{DISCUSSION}

In this study, we aimed to determine the role of RAGE in the progression of mesenteric IR-induced tissue injury and inflammation. Our hypothesis was that RAGE would contribute to the pathology associated with reperfusion injury, in line with its known pro-inflammatory role, and its documented role in 

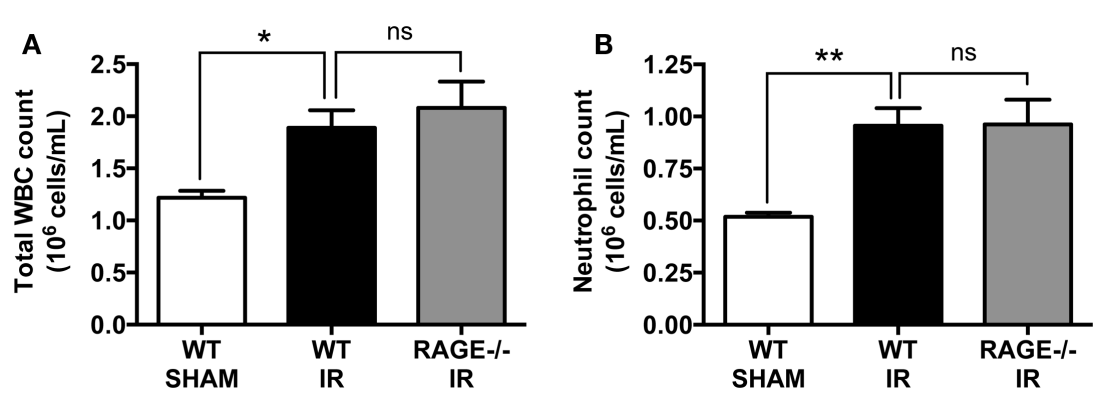

FIGURE 3 | Elimination of RAGE does not affect total white blood cell and blood neutrophil counts following intestinal IR. Mice were subjected to 30 min mesenteric artery occlusion, followed by 150 min reperfusion. The numbers of (A) white blood cells (WBC) and (B) neutrophils, in the peripheral blood collected after 150 min reperfusion, demonstrating that RAGE does not influence IR-induced leukocyte or neutrophil mobilization. Data are presented as mean \pm SEM, $n=5$ (WT-SHAM); $n=13(\mathrm{WT}-\mathrm{IR}) ; n=15\left(\mathrm{RAGE}^{-/-} \mathrm{IR}\right)$ where ${ }^{*} p<0.05,{ }^{* *} p<0.01$, and ns $=$ not-significant $(p>0.05)$.
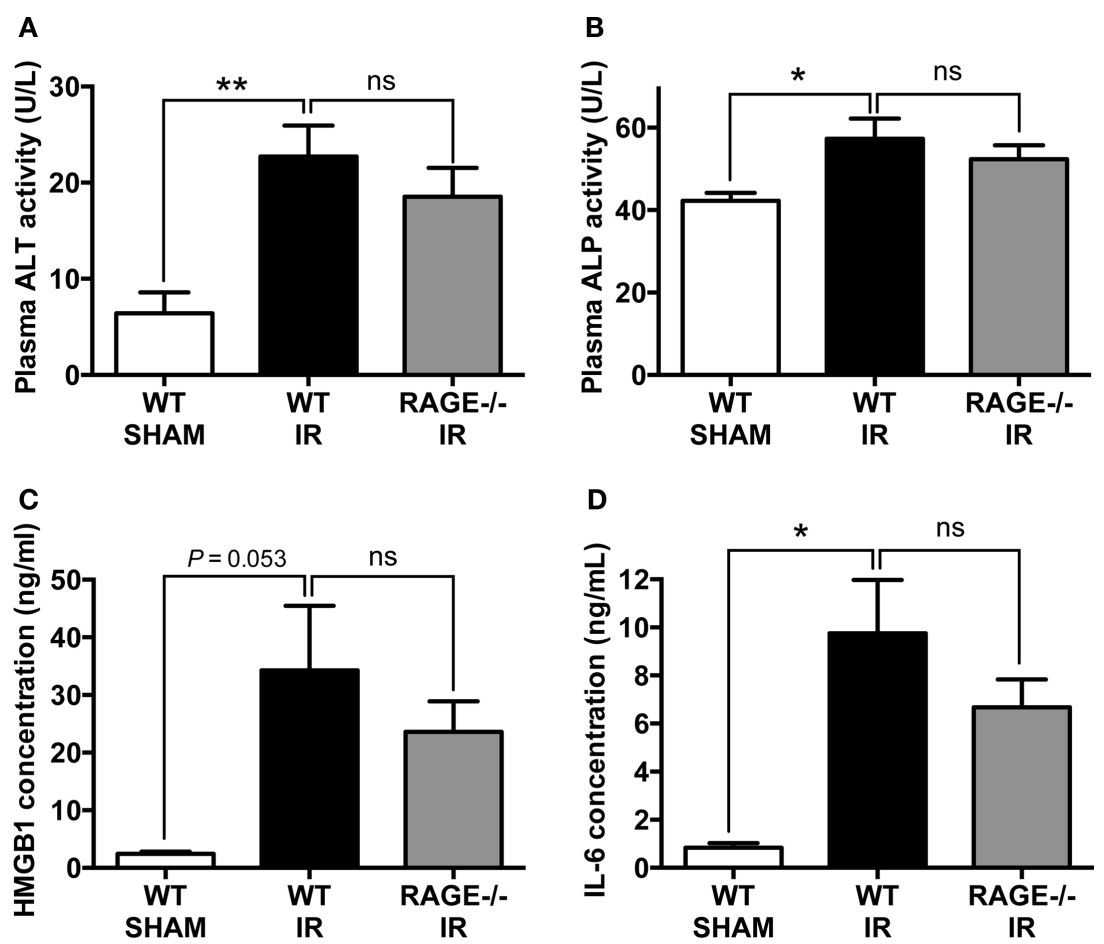

FIGURE 4 | Elimination of RAGE does not influence remote organ (liver) injury and systemic inflammation following intestinal IR. Mice were subjected to 30 min mesenteric artery occlusion, followed by 150 min reperfusion. Peripheral blood samples were collected from WT-SHAM, WT-IR, and RAGE ${ }^{-/-}$IR groups for enzyme activity and pro-inflammatory markers. (A,B) Activities of liver enzymes ALT (A) and ALP (B) measured as markers of liver injury. (C,D) Levels of pro-inflammatory mediators HMGB-1 (C) and IL-6 (D). Data are presented as mean \pm SEM, $n=5\left(\right.$ WT-SHAM); $n=13(\mathrm{WT}-\mathrm{IR}) ; n=15$ (RAGE ${ }^{-/-}$IR) where ${ }^{\star} p<0.05,{ }^{\star *} p<0.01$, and $n s=$ not-significant $(p>0.05)$.

propagating IR injuries in other organs (10-13). We first identified that ligands for RAGE, HMGB-1 and C3a, in the circulation were elevated after $30 \mathrm{~min}$ ischemia followed by $150 \mathrm{~min}$ reperfusion in the intestine, indicating that enhanced RAGEsignaling was feasibly increased after mesenteric IR. We then used $\mathrm{RAGE}^{-1-}$ mice to determine the effect of RAGE absence in intestinal IR injury. Interestingly, we found that all local and remote injury parameters measured including mucosal injury, intestinal edema and neutrophil infiltration, neutrophil mobilization and pro-inflammatory cytokine production, and liver injury markers were not altered by a lack of RAGE-signaling. Overall, these results clearly demonstrate that RAGE is not a critical receptor in the pathogenesis of intestinal IR-induced local injury, systemic inflammation and remote organ damage.

Mesenteric IR accounts for a high mortality rate in the hospital setting, and there is no adequate therapy. A severe proinflammatory response is seen upon reperfusion of the ischemic intestine, and leads to tissue destruction and remote organ failure. Thus, numerous therapies have been proposed to treat intestinal IR injury, particularly those targeting the innate immune system responding to alarmins produced by the ischemic tissue. RAGE is a key innate immune receptor that can interact with multiple 
and diverse ligands, many of which are produced following tissue ischemia, and has been reported to participate in a number of acute and chronic inflammatory diseases through downstream signaling mechanisms of immune and inflammatory responses (25-27). Indeed, in the setting of IR, several studies have described the pathogenic contribution of RAGE in injuries of the liver, lung, heart, and brain $(10-13,28)$.

One of the key ligands for RAGE is the secreted alarmin/DAMP HMGB-1, which has been clearly documented to mediate proinflammatory effects when activating this receptor $(7,29)$, and is suggested to be a key therapeutic target to reduce tissue injury $(11,12,30)$. In our mesenteric IR model, we demonstrated that the levels of HMGB-1 were significantly upregulated following IR. We also showed that another ligand for RAGE, the innate immune complement factor $\mathrm{C} 3 \mathrm{a}$ (31), was similarly elevated, indicating the potential for multiple ligands interacting with RAGE, which is expressed on many pro-inflammatory cells involved in IR, including within the intestine (32). Despite this potential for enhanced RAGE activation and pro-inflammatory induction, eliminating RAGE signaling in $\mathrm{RAGE}^{-/-}$mice did not protect local mucosal injury, neutrophil influx and vascular leakage, as well as remote organ liver damage caused by mesenteric IR. Interestingly, Dessing et al. (33) similarly showed that RAGE deficiency does not affect renal injury and function after renal IR, despite RAGE ligands HMGB-1 and S100B being expressed (33). They suggest that RAGE is likely not the primary effector of HMGB-1 in renal IR injury, but rather other innate immune receptors such as the toll-like receptors (TLRs) could be predominating in the proinflammatory response. Our study agrees with these findings, and indeed TLRs are known to play major roles in intestinal IR injuries (34).

RAGE-ligand interaction also leads to activation of proinflammatory transcription factor nuclear factor kappa B and its downstream target genes, inducing release of pro-inflammatory cytokines such as TNF, IL-1, IL-6, and IL-8 in different cell types $(35,36)$. We have previously shown IL- 6 to be a principal cytokine elevated in the circulation following mesenteric IR (18, 37). In this study, we found, however, that circulating IL-6 (or

\section{REFERENCES}

1. Stamatakos M, Stefanaki C, Mastrokalos D, Arampatzi H, Safioleas P, Chatziconstantinou $\mathrm{C}$, et al. Mesenteric ischemia: still a deadly puzzle for the medical community. Tohoku J Exp Med (2008) 216:197-204. doi:10.1620/tjem.216. 197

2. Yasuhara H. Acute mesenteric ischemia: the challenge of gastroenterology. Surg Today (2005) 35:185-95. doi:10.1007/s00595-004-2924-0

3. Sorkine P, Setton A, Halpern P, Miller A, Rudick V, Marmor S, et al. Soluble tumor necrosis factor receptors reduce bowel ischemia-induced lung permeability and neutrophil sequestration. Crit Care Med (1995) 23:1377-81. doi:10. 1097/00003246-199508000-00011

4. Hofmann MA, Drury S, Fu C, Qu W, Taguchi A, Lu Y, et al. RAGE mediates a novel proinflammatory axis: a central cell surface receptor for S100/ calgranulin polypeptides. Cell (1999) 97:889-901. doi:10.1016/S0092-8674(00) 80801-6

5. Ott C, Jacobs K, Haucke E, Navarrete Santos A, Grune T, Simm A. Role of advanced glycation end products in cellular signaling. Redox Biol (2014) 2:411-29. doi:10.1016/j.redox.2013.12.016

6. Liu R, Mori S, Wake H, Zhang J, Liu K, Izushi Y, et al. Establishment of in vitro binding assay of high mobility group box-1 and S100A12 to receptor
HMGB1) was not reduced by a lack of RAGE signaling in the IR pathological setting, suggesting a minor role of RAGE in mediating this cytokine release following mucosal injury due to IR. Furthermore, our results also demonstrate that RAGE does not contribute to the intestinal infiltration of neutrophils following mesenteric IR injury. In accordance with these data, leukocyte mobilization following intestinal IR was not altered by the absence of RAGE signaling. Together, this may contribute to the lack of tissue protection in $\mathrm{RAGE}^{-1-}$ mice, as neutrophils are known to be key mediators of IR-induced injury (14).

In conclusion, we highlight that deletion of RAGE signaling is not protective against IR-induced mucosal and remote organ injury and systemic inflammation, suggesting that RAGE does not play a role in the pathogenesis of intestinal IR injury in the mouse. Due to the multi-ligand nature of RAGE, in the absence of RAGE, these ligands may favor other pro-inflammatory receptors (such as toll-like receptors), and hence the protective effect of RAGE deletion may be effectively compensated for. Our study thus suggests that blockade of RAGE is not a credible therapeutic target for mesenteric IR injuries.

\section{AUTHOR CONTRIBUTIONS}

TW conceived the study and together with MW designed the experiments. MW and TG conducted the majority of experiments, with SM providing additional experimental support. MW, TG, and TW wrote the manuscript, with SM providing editorial assistance. All authors approved the final version of the manuscript.

\section{ACKNOWLEDGMENTS}

We thank author/Prof. Simon Phipps for providing the RAGE ${ }^{-/-}$ mice used in these studies.

\section{FUNDING}

This study was funded by the National Health and Medical Research Council of Australia (Project Grant APP1082271).

for advanced glycation endproducts: heparin's effect on binding. Acta Med Okayama (2009) 63:203-11.

7. Ruan BH, Li X, Winkler AR, Cunningham KM, Kuai J, Greco RM, et al. Complement C3a, CpG oligos, and DNA/C3a complex stimulate IFN-alpha production in a receptor for advanced glycation end product-dependent manner. J Immunol (2010) 185:4213-22. doi:10.4049/jimmunol.1000863

8. Litwinoff EMS, Hurtado Del Pozo C, Ramasamy R, Schmidt AM. Emerging targets for therapeutic development in diabetes and its complications: the RAGE signaling pathway. Clin Pharmacol Ther (2015) 98(2):135-44. doi:10.1002/cpt. 148

9. Walker D, Lue LF, Paul G, Patel A, Sabbagh MN. Receptor for advanced glycation endproduct modulators: a new therapeutic target in Alzheimer's disease. Expert Opin Investig Drugs (2015) 24:393-9. doi:10.1517/13543784. 2015.1001490

10. Zeng S, Feirt N, Goldstein M, Guarrera J, Ippagunta N, Ekong U, et al. Blockade of receptor for advanced glycation end product (RAGE) attenuates ischemia and reperfusion injury to the liver in mice. Hepatology (2004) 39:422-32. doi:10. 1002/hep. 20045

11. Andrassy M, Volz HC, Igwe JC, Funke B, Eichberger SN, Kaya Z, et al. Highmobility group box-1 in ischemia-reperfusion injury of the heart. Circulation (2008) 117:3216-26. doi:10.1161/CIRCULATIONAHA.108.769331 
12. Muhammad S, Barakat W, Stoyanov S, Murikinati S, Yang H, Tracey KJ, et al. The HMGB1 receptor RAGE mediates ischemic brain damage. J Neurosci (2008) 28:12023-31. doi:10.1523/JNEUROSCI.2435-08.2008

13. Sternberg DI, Gowda R, Mehra D, Qu W, Weinberg A, Twaddell W, et al. Blockade of receptor for advanced glycation end product attenuates pulmonary reperfusion injury in mice. J Thorac Cardiovasc Surg (2008) 136:1576-85. doi: 10.1016/j.jtcvs.2008.05.032

14. Schofield ZV, Woodruff TM, Halai R, Wu MC, Cooper MA. Neutrophils - a key component of ischemia-reperfusion injury. Shock (2013) 40:463-70. doi: 10.1097/SHK.0000000000000044

15. Constien R, Forde A, Liliensiek B, Grone HJ, Nawroth P, Hammerling G, et al. Characterization of a novel EGFP reporter mouse to monitor Cre recombination as demonstrated by a Tie2 Cre mouse line. Genesis (2001) 30:36-44. doi:10.1002/gene.1030

16. Liliensiek B, Weigand MA, Bierhaus A, Nicklas W, Kasper M, Hofer S, et al. Receptor for advanced glycation end products (RAGE) regulates sepsis but not the adaptive immune response. J Clin Invest (2004) 113:1641-50. doi:10.1172/ JCI200418704

17. Arumugam TV, Shiels IA, Woodruff TM, Reid RC, Fairlie DP, Taylor SM. Protective effect of a new $\mathrm{C} 5 \mathrm{a}$ receptor antagonist against ischemia-reperfusion injury in the rat small intestine. J Surg Res (2002) 103:260-7. doi:10.1006/jsre. 2002.6369

18. Wu MC, Brennan FH, Lynch JP, Mantovani S, Phipps S, Wetsel RA, et al. The receptor for complement component $\mathrm{C} 3 \mathrm{a}$ mediates protection from intestinal ischemia-reperfusion injuries by inhibiting neutrophil mobilization. Proc Natl Acad Sci U S A (2013) 110:9439-44. doi:10.1073/pnas.1218815110

19. Mantovani S, Gordon R, Macmaw JK, Pfluger CM, Henderson RD, Noakes PG, et al. Elevation of the terminal complement activation products C5a and C5b-9 in ALS patient blood. J Neuroimmunol (2014) 276:213-8. doi:10.1016/j. jneuroim.2014.09.005

20. Chiu CJ, McArdle AH, Brown R, Scott HJ, Gurd FN. Intestinal mucosal lesion in low-flow states. I. A morphological, hemodynamic, and metabolic reappraisal. Arch Surg (1970) 101:478-83. doi:10.1001/archsurg.1970.01340280030009

21. Woodruff TM, Strachan AJ, Sanderson SD, Monk PN, Wong AK, Fairlie DP, et al. Species dependence for binding of small molecule agonist and antagonists to the C5a receptor on polymorphonuclear leukocytes. Inflammation (2001) 25:171-7. doi:10.1023/A:1011036414353

22. Woodruff TM, Arumugam TV, Shiels IA, Reid RC, Fairlie DP, Taylor SM. Protective effects of a potent C5a receptor antagonist on experimental acute limb ischemia-reperfusion in rats. J Surg Res (2004) 116:81-90. doi:10.1016/j. jss.2003.04.001

23. Tian XF, Yao JH, Li YH, Gao HF, Wang ZZ, Yang CM, et al. Protective effect of pyrrolidine dithiocarbamate on liver injury induced by intestinal ischemiareperfusion in rats. Hepatobiliary Pancreat Dis Int (2006) 5:90-5.

24. Vollmar B, Menger MD. Intestinal ischemia/reperfusion: microcirculatory pathology and functional consequences. Langenbecks Arch Surg (2011) 396:13-29. doi:10.1007/s00423-010-0727-x

25. Clynes R, Moser B, Yan SF, Ramasamy R, Herold K, Schmidt AM. Receptor for AGE (RAGE): weaving tangled webs within the inflammatory response. Curr Mol Med (2007) 7:743-51. doi:10.2174/156652407783220714
26. Herold K, Moser B, Chen Y, Zeng S, Yan SF, Ramasamy R, et al. Receptor for advanced glycation end products (RAGE) in a dash to the rescue: inflammatory signals gone awry in the primal response to stress. J Leukoc Biol (2007) 82:204-12. doi:10.1189/jlb.1206751

27. Chuah YK, Basir R, Talib H, Tie TH, Nordin N. Receptor for advanced glycation end products and its involvement in inflammatory diseases. Int J Inflam (2013) 2013:403460. doi: $10.1155 / 2013 / 403460$

28. Hassid BG, Nair MN, Ducruet AF, Otten ML, Komotar RJ, Pinsky DJ, et al. Neuronal RAGE expression modulates severity of injury following transient focal cerebral ischemia. J Clin Neurosci (2009) 16:302-6. doi:10.1016/j.jocn. 2007.12.011

29. Lotze MT, Tracey KJ. High-mobility group box 1 protein (HMGB1): nuclear weapon in the immune arsenal. Nat Rev Immunol (2005) 5:331-42. doi:10.1038/ nri1594

30. Kokkola R, Andersson A, Mullins G, Ostberg T, Treutiger CJ, Arnold B, et al. RAGE is the major receptor for the proinflammatory activity of HMGB1 in rodent macrophages. Scand J Immunol (2005) 61:1-9. doi:10.1111/j.0300-9475. 2005.01534.x

31. Coulthard LG, Woodruff TM. Is the complement activation product C3a a proinflammatory molecule? Re-evaluating the evidence and the myth. J Immunol (2015) 194:3542-8. doi:10.4049/jimmunol.1403068

32. Heijmans J, Buller NV, Hoff E, Dihal AA, van der Poll T, van Zoelen MA, et al. Rage signalling promotes intestinal tumourigenesis. Oncogene (2013) 32:1202-6. doi:10.1038/onc.2012.119

33. Dessing MC, Pulskens WP, Teske GJ, Butter LM, van der Poll T, Yang $\mathrm{H}$, et al. RAGE does not contribute to renal injury and damage upon ischemia/reperfusion-induced injury. I Innate Immun (2012) 4:80-5. doi:10. $1159 / 000334251$

34. Arumugam TV, Okun E, Tang SC, Thundyil J, Taylor SM, Woodruff TM. Tolllike receptors in ischemia-reperfusion injury. Shock (2009) 32:4-16. doi:10. 1097/SHK.0b013e318193e333

35. Andersson U, Wang H, Palmblad K, Aveberger AC, Bloom O, ErlandssonHarris $\mathrm{H}$, et al. High mobility group 1 protein (HMG-1) stimulates proinflammatory cytokine synthesis in human monocytes. J Exp Med (2000) 192:565-70. doi:10.1084/jem.192.4.565

36. Kierdorf K, Fritz G. RAGE regulation and signaling in inflammation and beyond. J Leukoc Biol (2013) 94:55-68. doi:10.1189/jlb.1012519

37. Woodruff TM, Wu MCL, Morgan M, Bain NT, Jeanes A, Lipman J, et al EphA4-Fc treatment reduces ischemia/reperfusion-induced intestinal injury by inhibiting vascular permeability. Shock (2016). in press.

Conflict of Interest Statement: The authors declare that the research was conducted in the absence of any commercial or financial relationships that could incur a potential conflict of interest.

Copyright (C) 2015 Wu, Gilmour, Mantovani and Woodruff. This is an open-access article distributed under the terms of the Creative Commons Attribution License (CC $B Y)$. The use, distribution or reproduction in other forums is permitted, provided the original author(s) or licensor are credited and that the original publication in this journal is cited, in accordance with accepted academic practice. No use, distribution or reproduction is permitted which does not comply with these terms. 